The formulae necessary to work with Gauss' method are explained, the observables and the errors to combat are adequately described. The second order terms are fully developed. The authors give full information on how to observe universal time and latitude, and how chain observations of groups are to be used. The influence of errors in astronomical constants used is treated. As is well known, Gauss' method found its full application only after Danjon conceived his "astrolabe impersonnel", and a description of this, now famous, instrument is given. The method of deriving relative corrections of star positions, together with Krejnin's proposal to obtain absolute declinations is given, together with full numerical examples. The only item which was found missing is Guinot's proposal to improve on Danjon's instrument, to introduce a full-aperture astrolabe. The book deserves to be studied carefully, the outlook and quality is excellent.

\title{
ERRATA TO THERMOPHYSICS OF THE PLANET MERCURY
}

\author{
DAVID MORRISON
}

(Original paper in Space Science Reviews 11 (1970), 271-307.)

On page 277 , a factor of $\sqrt{ } \varepsilon$, where $\varepsilon$ is the dielectric constant, was omitted from Equation 4. This equation should read:

$$
\delta=\frac{\lambda}{2 \pi \sqrt{\varepsilon \tan \Delta}}\left(\frac{\pi \varrho c}{K P}\right)^{1 / 2} .
$$

On page 298 , in the second line above the figure, the wavelength should read $6.0 \mathrm{~cm}$, rather than $0.6 \mathrm{~cm}$. 